\section{THE PREVALENCE OF LOW BACK PAIN IN CRICKETERS - AN UNDERGRADUATE EPIDEMIOLOGICAL STUDY}

\author{
by Ian Harris, Dept of Physiotherapy, \\ University of Cape Town
}

\section{INTRODUCTION}

Cricket in South Africa plays a major socio-economic role and, through innovations such as the one day limited overs and day-night games, is increasingly drawing the attention of large crowds throughout the country.

Cricket is becoming far more aggressive and faster ${ }^{3}$ and is placing greater strains on thecricketer's body. The lumbar area of the cricketer is one of the areas that is being placed under increased strain, especially in the fast bowling action ${ }^{2}$. This is taking place at a time when, with increased professionalism, cricketers can least afford to be affected by disabling injuries, such as Low Back Pain (LBP).

LBP in itself has far reaching affects on the general community with as much as $5 \%$ of all time absent from work being attributed to $\mathrm{LBP}^{3}$. With the added stresses and strains of modern cricket, epidemic levels of LBP are expected amongst cricketers. The problem of LBP is further aggravated by the difficulty of making an accurate diagnosis. LBP is often characterised by the stooped appearance associated with old age which could be harmful to the self esteem of a cricketer with LBP. Therefore, LBP is not frequently discussed by the cricketing fraternity, making it extremely difficult to ascertain the true extent of LBP in cricketers.

The dearth of research on cricket in South Africa and the changing nature of the game challenges science and medicine to explore the various aspects of the game.

\section{METHOD}

A questionnaire was given directly to 110 cricketers, 55 from the first teams of

\section{continued from page 64}

the knee-joint. Physiotherapists treating cycling-related injuries should not treat purely symptomatically, and a thorough knowledge of the above-mentioned factors is imperative. The distinguishing trademark of the effective practitioner in this case will not be her knowledge of physiotherapy, but her knowledge of the sport.

\section{REFERENCES}

1. Friedman GD. Primer of Epidentiology 1980. McGraw Hill, New York

2. Kiburz Z, Jacobs R, Reckling F et al. Bicycle Accidents and Injuries among Adult Riders. five cricket clubs and from five schools in the Western Cape during the 1991/92 season. The questionnaire consisted of an initial set of close-ended questions as well as a further set of open-ended questions which allowed the respondents to voice their opinions.

A grading scale of pain severity was used to measure LBP. The pain being graded as follows: Grade 1, an ache but could continue playing, Grade 2, pain which forced the player to leave the field and Grade 3, pain which prevented the playing of a match. Each respondent was classified as either a fast bowler (FB), slow bowler (SB), batsmen (BAT) and a wicket keeper (WK).

Numerous cricket practices and matches were visited in order to gain general information on warm-up methods, different techniques shown and to obtain a feel for the cricketers' personalties and idiosyncrasies.

The data obtained from the questionnaire was presented by means of descriptive statistics with null hypotheses being formulated and tested by appropriate statistical tests.

\section{RESULTS}

The return response was $90 \%$. The mean age was 20.2 years with a range of between 15 and 35 years, with $55.6 \%$ of respondents being above 18 years old and $44.4 \%$ were younger than 18 years. The mean number of years playing cricket was 12.3 years with a range between 3 and 27 . The respondents consisted of $37.4 \% \mathrm{FB}, 58,6 \% \mathrm{BAT}, 27.3 \%$ SB and $11.1 \%$ WK.

\section{PREVALENCE OF INJURY}

LBP was present in $61.6 \%$ of the cricketers and, of these, $78,7 \%$ cited cricket as being the cause of the LBP.

\section{SEVERITY OF INJURY}

Grade 1 injuries were most prevalent (72.1\%), although Grade 3 injuries oc-

Am Jnl Sports Med 1986;14(5):416-419.

3. van Velden DP, Roberts T, Human E et al. Fietsry vir Almal (1st Ed.) 1990. Tafelberg Uitgewers, Kaapstad.

4. McLeod WD, Blackburn TA. Biomechanics of Knee Rehabilitation with Cycling. Am Inl Sports Med 1980;8(3):175-180.

5. Reilly T. Sports Fitness and Sports Injuries (3rd Ed.) 1981. Faber \& Faber, London.

6. Bohlman JT. Injuries in Competitive Cycling. The Phys \& Sports Med 1981;9(5):117-126.

7. Town GP. Science of Triathlon Training and Competition (1st Ed.) 1985. Human Kinetics Publishers, Champaign, Illinois.

8. Hannaford DR, Moran GT, Hlavad HF. Video Analysis and Treatment of Over-use Kneè Injury in Cycling: A Limited Clinical Study Clin in Podiatric Med and Surg 1986;34:671678.

\section{ABSTRACT}

The prevalence of Low Back Pain (LBP) in cricketer's was determined and possible causative factors were investigated. Questionnaires were sent to 110 cricketers playing for their first times of both clubs and schools during the $1991 / 92$ season. The return response was $90 \%$ with a prevalence of LBP at $61.6 \%$. Of these $78.7 \%$ cited cricket as being the primary cause of their LBP. The injuries were predominantly grade $1(72.1 \%)$, lollowed by grade 3 $(23.1 \%)$ and grade $2(6.6 \%)$. Grading was made according to the effect the pain had on the cricketers game. Fast bowlers proved to be more al risk of developing LBP with a group prevalence of $75.6 \%$ followed by wicket keepers at $63.6 \%$, batsmen at $56.8 \%$ and slow bowlers at $48.1 \%$. Cricketers had rather a poor general knowledge of ways of protecting their backs. Recommendations were made to help reduce the high prevalence of LBP, especially amongst Fast bowlers and in cricketers in general.

curred in a large group (21.3\%). A further indicator of severity is the large number $(62.3 \%)$ of cricketers who required treatment for their LBP.

\section{GROUP PREVALENCE}

The largest proportion of LBP was amongst the fast bowlers $(75.6 \%)$ which proved to be statistically significant with an obtained p-value of 0.06 using the Chisquared test. Furthermore, it was found that there was a higher prevalence of LBP in FB's with a front-on action (85.7\%) than in those with a side-on action $(72.4 \%)$. The group of front-on bowlers was too small for statistical testing.

\section{OTHER FACTORS}

Of the factors investiga ted (age, number of years playing, warm-up, various types of exercises, knowledge of prevention of injuries), the only one that proved to be significant was the lack of knowledge that cricketers had of ways to protect their backs. Of those cricketers who had LBP, only $55.7 \%$ said they knew how to protect their backs. Age did not prove to be a significant predictor of LBP.

9. McLennan JG, McLennan JC, Ungersma J. Accident Prevention in Competitive Cycling Am Jnl Sports Med 1988:16(3):266-273.

10. Kruze DL, McBeath AA. Bicycle Accidents and Injuries Am Inl Sports Med 1980;8:342344.

11. Tucci JJ, Barone JE. A Study of Urban Bicycling Accidents Am Inl Sports Med 1988;16(2):181-184.

12. Balham A, Absoud Em, Kotecha MB. A Study of Bicycle Accidents Injury Am Jnl Sports Med 1988;16(6):405-408.

13. Malhoney F. Bicycling Magazine's complete Guide to Riding and Racing Techniques. 1979.

14. Dubb I, Jacobs L, Sutton P. Injuries in $\mathrm{Cy}$ clists. Physio Forum 1989;3/90:12.

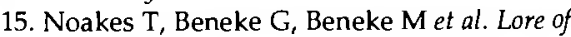
Cycling 1990. Oxford University Press, Cape Town. 


\section{DISCUSSION}

\section{PREVALENCE OF LOW BACK PAIN}

The prevalence of LBP found in this study compares well with the 48 serious and less serious back injuries found in a study of 92 first class cricketers by Stretch ${ }^{4}$.

The large proportion of grade 1 injuries may be attributed to soft tissue problems such as the myofascial pain syndrome, with the back showing signs of stiffness and weakness ${ }^{5}$.

Another possible explanation for the high incidence of minor injuries is the extrovert personality type of most cricketers, which makes them tend to underplay their injuries. It must also be borne in mind that LBP, even if it is an innocuous strain, can be totally disabling. The high percentage of cricketers requiring treatment adds strength to the above statement.

\section{GROUP PREVALENCE}

The bowlers $(75.6 \%)$ proved to be the most at risk of developing LBP. This was confirmed in the study of first class cricketing injuries in South Africa by Stretch, which showed $65.7 \%$ of LBP was caused by bowling ${ }^{4}$. The studies done by Stretch and this study were focussed on assessment of severity rather than a diagnosis of LBP. If more accurate diagnosis of pathology using computerised topography was used the findings may have been different ${ }^{6}$.

The high prevalence of LBP in fast bowlers is not surprising when one considers that the fast bowling absorbs three times their body weight at run-up and up to four times their body weight at front and rear foot contact during the delivery stride.

These absorption forces, together with a spine that is laterally flexing, rotating, extending and being compressed, can cause trauma which, despite being below the threshold that muscles and joints can tolera te, is able to produce injury due to the repetitive nature of fast bowling ${ }^{7}$. The repetitive nature of fast bowling can be illustrated by a work to rest ratio which has been calculated as $1: 3^{8}$. This means that, although the repeated trauma is below the threshold that joints and musculotendinous structures can tolerate, injury may well occur.

Foster suggests that there is a combination of factors responsible for LBP, including one or more inadequate physical and/or physiological attributes, poor bowling technique, high physical demands and sudden increases in training ${ }^{7}$. This was confirmed by Meuleman who stated that changes in bowling technique have caused many of the fast bowler injuries ${ }^{9}$. Despite the fact that the front-on and the side-on technique have similar forces on front foot impact, the side-on technique allows the body to summate body forces more effectively ${ }^{2}$.

\section{KNOWLEDGE OF PROTECTION}

Although knowledge of protection may be an unusual concept to investigate, it needs to be further explored. Physiotherapists havefor years been involved in treating LBP and more recently have embarked on preventative programmes, through in creasing the public's awareness of the possible causes of LBP. However, not much has been done in order to educate sportsmen regarding the dangers that their backs are exposed to due to the specific mechanics of their sport. The distinct lack of knowledge found in this study, together with poor bowling technique and inadequate strength and flexibility training are causes of LBP in cricketers. Clearly we have a responsibility to increase the awareness of cricketers regarding the problem of LBP.

\section{OTHER FACTORS}

There was no relationship between the age group and the prevalence of LBP. This is in keeping with Micheli who noted an increase in adult type injuries now occurring in children ${ }^{10}$. Overuse injuries in areas such as stress fractures to the pars interarticularis and the growth cartilage are on the increase, as children become more heavily involved in cricket. Children are more susceptible to overuse injuries than adults because of the effect it has on structures that are not yet mature.

There was also no relationship between the number of years that cricket was played and LBP. However, the number of years of playing cricket wasn't truly representative of the repetitive nature of cricket, and does not describe the number of repetitive activities involved in a cricketer's year.

\section{CONCLUSION}

This study can be seen as a stepping stone to further research in the complex area of LBP. Fortunately South Africans have a deep desire to produce champions, and this desire in both the cricketing authorities and the players will recognise and support further studies.

\section{RECOMMENDATIONS}

There is a great need for continuing research in to the possible causes of LBP in cricketers, especially in fast bowlers with populations which are far more diverse and ranging from schoolboy cricketers right through to international level cricketers.

The health professions must realise that their involvement in treating cricket injuries is an important one, not only by decreasing the cricketer's pain but also by restoring him to normal functioning on the cricket field. The way this can be achieved is by taking into account the cricketer, his personality and the cricketing environment.
Coaches, cricketers and administrators will have to accept their role in tackling the problem of LBP. Science of the sport suggests good leg, back and trunk flexibility as well as strength to reduce the large forces placed on the low back. Excessively long bowling spells must be avoided, especially in the young and those who aren't accustomed to a heavy workload. Good technique, without destroying individual flair and a quality warm up should be undertaken at all times, and cricketers themselves encouraged to take responsibility for protecting their backs.

\section{COMMENT FROM REFEREES}

If the aim of the study was only to identify the prevalence of low back pain in cricketers, then it would have been worthwhile to provide normative data for the age group studied. The scale used to measure pain is limited and a more accurate measurement would have enhanced the study.

\section{REFERENCES}

1. Temple R. Cricket injuries: Fast Pitches Change the Gentlemen's Sport. The Physician and Sports Medicine June 1982;6(10).

2. Elliot BC, Foster DH. A Biomechanical Analysis of the Front-on and side-on bowling techniques. Journal of Movement Studies 1984;10:83-94.

3. Calliet R. Low Back Pain Syndrome. FA Davis Company, Philadelphia 1981:5.

4. Stretch RA. Injuries to South African cricketers playing at First Class Level. South African Journal of Sports Medicine 1989;4(1):3-20.

5. Travell JG, Simons DG. Myofascial Origins of Low Back Pain. Postgraduate Medicine Feb 1983;73(2)

6. Foster D, Elliot B, Ackland et al. Back Injuries to Fast Bowlers in Cricket: A Prospective Study. British Journal of Sports Medicine Sept 1989;2(4):40-47.

8. Radin EL, Simon SR, Rose RM et al. Practical Biomechanics for the Orthopaedic Surgeon. J Wiley and Sons, New York 1979.

9. Meuleman K. Quickies are the workhorses. In the Sunday Independent Newspaper 6 March 1983, Perth.

10. Micheli LJ et al. Aetiological assessment of overuse stress fractures in athletes. Nov Scotia Med Bull 1983;59:43-47.

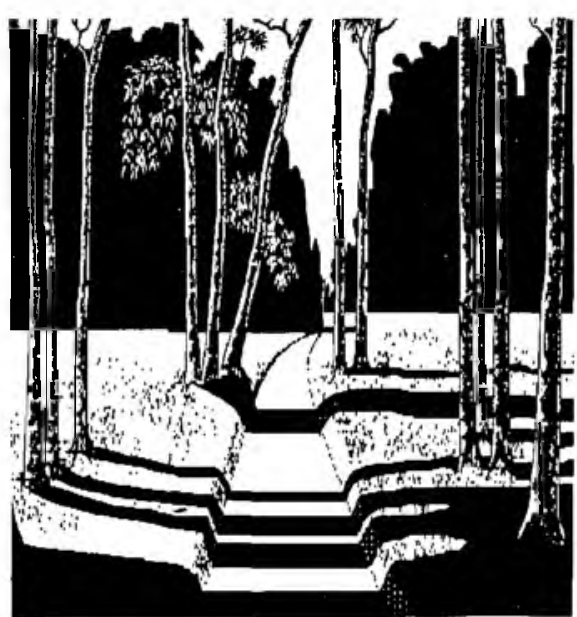

